\title{
Commentary on "Risk factors and outcome of repair of obstetric anal sphincter injuries as followed up in a dedicated perineal clinic"
}

\author{
Abdelmageed Abdelrahman ${ }^{1}$ \\ Received: 10 May 2019 / Accepted: 30 May 2019 / Published online: 20 June 2019 \\ (C) The International Urogynecological Association 2019
}

This was a prospective cohort study of all patients attending a postnatal perineal clinic 4-12 months postpartum. This study took place between January 2016 and October 2017 at the National Maternity Hospital in Dublin. Women attending the perineal clinic completed the St. Mark Questionnaire. This questionnaire scores symptoms of flatus, solid and liquid stool incontinence. It also accounts for alterations in lifestyle, the need for constipating agents and the degree of faecal urgency. Women underwent endoanal ultrasound and a digital rectal examination. The authors collected demographic data including maternal age, parity at time of delivery, mode of delivery, use of mediolateral episiotomy, induction, epidural anaesthesia, length of second stage of labour, occipito-posterior position, shoulder dystocia and birth weight.

A total of 57 women were reviewed following a major tear (3C tear or 4th degree tear) and 310 were reviewed following a minor tear (3A tear or 3B tear). In summary, the authors concluded that women who had an instrumental delivery were more likely to have a $3 \mathrm{C}$ or 4 th degree tear than those who had a spontaneous vaginal delivery. They also highlight the importance of having a dedicated perineal clinic for the investigation and management of obstetric anal sphincter injuries.

Abdelmageed Abdelrahman

abdelmageed@hotmail.co.uk

1 Department of Urogynaecology, Liverpool Women's Hospital NHS Foundation Trust, Liverpool, UK
Strengths of this study include being prospective and that it uses a validated incontinence questionnaire which allows for differentiation of incontinence type based on patients' selfreporting. Another strength of the study was the review process, were all patients were reviewed by a single consultant gynaecologist. This allowed for consistent work-up and uniformity of assessments (endoanal ultrasound and digital rectal examination). Limitations of the study include the position at birth not being documented in just over half of cases in addition to other important factors, such as length of labour and length of the second stage.

\section{Compliance with ethical standards}

Conflicts of interest None.

Publisher's note Springer Nature remains neutral with regard to jurisdictional claims in published maps and institutional affiliations. 